\title{
The relevance of the intrinsic subtype to the clinicopathological features and biomarkers in Japanese breast cancer patients
}

\author{
Masako Tamaki ${ }^{1}$, Takako Kamio ${ }^{1 *}$, Shingo Kameoka ${ }^{1}$, Noriko Kojimahara ${ }^{2}$ and Toshio Nishikawa ${ }^{3}$
}

\begin{abstract}
Background: Breast cancer is a disease rich in diversity, and it can be categorized into the immunohistochemical intrinsic subtypes: ER/PR + and HER2-, ER/PR + and HER2+, HER2 type, basal-like and unclassified.

Methods: In this study, in addition to the clinicopathological features potentially associated with the intrinsic subtypes, protein expression and genetic mutations of key molecules associated with breast cancer prognosis and treatment sensitivity were analyzed. The distribution of subtypes in the patient population and the differences in marker distribution across the subtypes were investigated.

Results: The immunohistochemical features of 471 consecutive surgical cases of women with primary breast cancer, treated in a single institution, were examined. There were 306 patients who were ER/PR + HER2- (65\%); 41 who were ER/PR + HER2+ (8.7\%); 59 with HER2 type (12.5\%); 37 with basal-like (7.9\%); and 28 patients whose breast cancer was unclassified (5.9\%). There were no significant differences between the subtypes regarding age, menopausal status, disease stage, lymphatic invasion, blood vessel invasion and lymph node metastasis. Statistically significant differences were found for histological type and grade. Regarding protein expression and genetic mutation, significant differences were found in the distribution within each subtype for six out of 12 molecules investigated.

Conclusions: This study revealed that subtypes differ not only in their clinical pathological profiles, such as histological types and histological grades, but also in molecular expression. The molecular expression patterns observed for each intrinsic subtype may help the selection of an optimal treatment strategy.
\end{abstract}

\section{Background}

Breast cancer is a disease rich in diversity, and it can be categorized into subtypes with distinct biological features. Sorlie et al. showed that breast cancer can be divided into five 'intrinsic subtypes' by gene expression analysis using a DNA microarray [1]. Subsequently, Carey et al. reported that breast cancers can be divided into the five intrinsic subtypes by a protein expression analysis of estrogen receptor (ER), progesterone receptor (PR), human epidermal growth factor receptor type 2 (HER2), epidermal growth factor receptor (EGFR) and cytokeratin 5 or $6(\mathrm{CK} 5 / 6)$, using immunohistochemistry (IHC) [2]. This IHC-intrinsic subtyping is now widely used [3-6].

\footnotetext{
* Correspondence: ako@surg2.twmu.ac.jp

'Department of Surgery II, Tokyo Women's Medical University, 8-1

Kawada-cho, Shinjuku-ku, Tokyo 162-8666, Japan

Full list of author information is available at the end of the article
}

The biological characteristics and the clinical presentations differ between the five intrinsic subtypes [1-6]. Intrinsic subtypes can be useful as reference data in the existing treatment selection process. Moreover, the development of new treatments for breast cancer may need to take into consideration the intrinsic subtypes. Distribution data, or prevalence (the proportion of each subtype in the patient population), and knowledge of the clinicopathological features associated with each subtype are being accumulated regarding intrinsic subtypes [1-6]. However, there have so far been few reports on biomarker protein expression and genetic mutation profiles for the intrinsic subtypes, particularly in Japanese populations. Therefore, in this study, the distribution of key molecules associated with breast cancer prognosis and treatment sensitivity was investigated, in addition to subtype distribution and associated clinicopathological characteristics.

\section{Biomed Central}

(c) 2013 Tamaki et al.; licensee BioMed Central Ltd. This is an open access article distributed under the terms of the Creative Commons Attribution License (http://creativecommons.org/licenses/by/2.0), which permits unrestricted use, distribution, and reproduction in any medium, provided the original work is properly cited. 
More specifically, the protein expression of phosphatase and tensin homolog deleted on chromosome 10 (PTEN), insulin-like growth factor-1 receptor (IGF-1R), B-cell lymphoma 2 (Bcl-2), c-Kit, hepatocyte growth factor receptor (c-Met), hypoxia-inducible factor 1-alpha (HIF$1 \alpha$ ), alpha-type platelet-derived growth factor receptor (PDGFRA), survivin, vascular endothelial growth factor receptor 2 (VEGFR2), vascular endothelial growth factor A (VEGF-A), in addition to ER, PR, HER2, EGFR, CK5/6, and PIK3CA genetic mutation were analyzed. And the differences in biomarker distribution among the subtypes were investigated. PTEN loss and expression of c-Kit, c-Met, HIF-1 $\alpha$, PDGFRA VEGFR2, and VEGF-A have been reported to be worse prognostic factors for breast cancer, whereas expression of IGF-1R, Bcl-2 and survivin are reportedly good prognostic factors for breast cancer.

Ethnic differences have been reported in the prevalence of intrinsic subtypes and associated clinicopathological features [2], and so it is desirable to accumulate information on the targeted ethnic group when selecting or developing treatments. In Japan, there have so far been only a few reports that have investigated the prevalence of intrinsic subtypes. The results of this study are expected to make a significant contribution to the growing body of data regarding Japanese patients.

\section{Methods}

\section{Patients}

Candidates for this investigation comprised 471 consecutive surgical cases of women with primary breast cancer who were treated in the Department of Surgery II, Tokyo Women's Medical University throughout July 2004 to November 2007, excluding patients in whom pre-surgical treatment was performed. In cases of bilateral breast cancer, each tumor was separately set as a sample, and for cases of multiple breast cancer, only the main tumor was set as a sample and investigated.

\section{Ethical approval}

This study protocol was approved by the Ethical Committee of Tokyo Women's Medical University. This is an observational study by using stored samples and existing medical records. Only investigators in Tokyo Women's Medical University have been allowed to access data with personal information.

\section{Methods}

Clinicopathological characteristics (menopausal status, disease stage, histological type, histological grade, tumor size, lymphatic invasion, blood vessel invasion, lymph node metastasis), protein expression and genetic mutation were investigated. The differences in distribution between each subtype were statistically examined and analyzed. Key biomarkers in breast cancer prognosis and treatment sensitivity were selected, and their protein expression was measured by IHC. Gene mutation in PIK3CA exons 9 and 20 was detected by PCR amplification followed by direct sequencing.

\section{Protein expression analysis}

In addition to ER, PR, HER2, EGFR and CK5/6, which are required for subtyping, 10 other molecules reported to be predictive for breast cancer prognosis and sensitivity to treatment were assessed: PTEN, IGF-1R, Bcl-2, c-Kit, c-Met, HIF-1 $\alpha$, PDGFRA, survivin, VEGFR2 and VEGR-A. For HER2, fluorescence in situ hybridization was done when IHC was scored as 2+. CK5/6 IHC was performed on only the triple negative breast tumors (ER-,PR- and HER2-). The assay conditions and scoring criteria of IHC assays are shown in the Table 1.

Intrinsic subtypes were assigned as follows: ER/PR + HER2- (ER + and/or PR+, and HER2-); ER/PR + HER2+ (ER + and/or PR+, and HER2+); HER2 type (ER-, PR- and HER2+); basal-like (triple negative; ER-, PR-, HER2-, and EGFR+ and/or CK5/6+); and unclassified (ER-, PR-, HER2-, EGFR- and CK5/6).

\section{Mutation analysis}

Genomic DNA was extracted from paraffin-embedded tumor tissue sections using DEXPAT ${ }^{\circ}$ (Takara Bio Inc., Shiga Japan). Genomic DNA was amplified by PCR using the specific amplifying primers for exons 9 and 20 of PIK3CA. The mRNA sequence for PIK3CA was obtained from GenBank [GenBank:NM_006218]. Since exon 20 is relatively large (271 bp), the first and second halves of the gene were separately amplified with one overlapping region of 57 base pairs. The purified PCR products were sequenced using BigDye ${ }^{\bullet}$ Terminator Cycle Sequencing Kit (Applied Biosystems, Foster City, CA, USA) and analyzed with an automated capillary ABI PRISM 3100 genetic analyzer (Applied Biosystems). The DNA chromatograms were analyzed using the SeqScape ${ }^{\circ}$ ver2.5 software (Applied Biosystems) for any single mutations, followed by visual confirmation. All mutations identified were confirmed by a second analysis by independent PCR amplification and direct sequencing. Genomic DNA from corresponding normal tissue was subjected to sequence analysis to confirm that the nucleotide substitutions detected in tumor tissues were somatic rather than germline mutations.

\section{Statistical methods}

Analysis of variance, Fisher's exact probability test and Cochran-Mantel-Haenszel test were performed to evaluate the statistical significance of any variation in biomarker prevalence and clinicopathological features within the subtypes, using SAS software version 9.1.3. For the statistical 
Table 1 Experimental conditions of immunohistochemistry assays

\begin{tabular}{llll}
\hline Antibody (clone) & Dilution & Source & Criteria for positive/negative \\
\hline ER : Antibody (ID5) & $\times 100$ & Dako & Positive: Stained cells $>10 \%$ \\
PR : Antibody (PgR636) & $\times 500$ & Dako & Positive: Stained cells $>10 \%$ \\
HER2 (HercepTest) & Ready to use & Dako & HercepTest criteria \\
EGFR (EGFR pharmDx kit) & Ready to use & Dako & EGFR pharmDx kit criteria \\
CK5/6 (D5/16 B4) & $\times 100$ & Dako & Positive: Stained cells $>10 \%$ \\
PTEN (6H2.1) & $1: 100$ & Dako & - No staining \\
& & & Decreased staining intensity \\
& & & ++ Equal or increased staining intensity \\
IGF-1R (C-20) & $1: 50$ & Santa Cruz & Score 0, 1+, 2+, 3+ using HercepTest criteria \\
BCl-2 (124) & $\times 50$ & Dako & Positive: Stained cells $>10 \%$ \\
C-Kit (polyclonal; CD117) & $\times 500$ & Dako & Positive: Stained cells $>10 \%$ \\
C-Met (C-28, polyclonal) & $1: 100$ & IBL & Positive: Stained cells $>10 \%$ \\
HIF-1a (H1alpha67) & $\times 100$ & Novus Biologicals & Positive: Stained cells $>10 \%$ \\
PDGFRA (C20, polyclonal) & $1: 200$ & Thermo & Positive: Stained cells $>10 \%$ \\
Survivin (12C4) & $\times 200$ & Novus Biologicals & Positive: Stained cells $>20 \%$ \\
VEGFR2 (polyclonal; Flk-1(A-3)) & $\times 100$ & Santa Cruz & Positive: Stained cells $>10 \%$ \\
VEGF-A (VG1) & Ready to use & Thermo & Positive: Stained cells $>10 \%$
\end{tabular}

ER: estrogen receptor, PR: progesterone receptor, HER2: human epidermal growth factor receptor type 2, EGFR: epidermal growth factor receptor, CK5/6: cytokeratin 5 or 6, PTEN: phosphatase and tensin homolog deleted on chromosome 10, IGF-1R: insulin-like growth factor-1 receptor, Bcl-2: B-cell lymphoma 2, c-Met: hepatocyte growth factor receptor, HIF-1a: hypoxia-inducible factor 1-alpha, PDGFRA: alpha-type platelet-derived growth factor receptor, VEGFR2: vascular endothelial growth factor receptor 2, VEGF-A: vascular endothelial growth factor A.

NOTE. Dako: Tokyo, Japan. Santa Cruz: Tokyo, Japan. IBL: Gunma, Japan. Novus Biologicals: Littleton, Colorado, USA. Thermo: Waltham, Massachusetts, USA

differences between each group, a P-value under 0.05 was regarded as statistically significant. Exact odds ratio and 95\% CI adjusted by age strata (except for menopausal status) were estimated by using SAS 9.1.3 Freq procedure.

\section{Results}

The clinicopathological features for each intrinsic subtype as determined by the expression of ER, PR, HER2, EGFR and CK5/6 are shown in Table 2. Out of the 471 patients, there were 306 who were ER/PR + HER2(65.0\%), 41 who were ER/PR + HER2+ (8.7\%), 59 of HER2 type (12.5\%), 37 of basal-like (7.9\%) and 28 patients of unclassified (5.9\%).

There was no significant difference across the subtypes in age, menopausal status, disease stage, lymphatic invasion, blood vessel invasion or lymph node metastasis (Level I to III). Significant differences in the distribution between the intrinsic subtypes was observed when the cancer was divided into five histological types, namely papillotubular carcinoma, solid-tubular carcinoma, scirrhous carcinoma, noninvasive carcinoma/Paget's disease, and others. Scirrhous carcinoma was more frequent in ER/PR + HER2- and ER/PR + HER2 + cases, at $47 \%$ and $46 \%$, respectively. Papillotubular carcinoma, scirrhous carcinoma and solid-tubular carcinoma occurred at almost the same frequency for HER2 type, and the frequency of solid-tubular carcinoma was higher for patients with basal-like IHC compared to other groups, at $62 \%$. Moreover, there was a significant difference among the intrinsic subtypes in the distribution of three histological types, namely papillotubular carcinoma, solid-tubular carcinoma and scirrhous carcinoma $(P<0.01)$. When tumor size and histological grades of the 406 cases of invasive carcinoma, excluding noninvasive carcinoma and Paget's disease, were compared among intrinsic subtypes, no significant differences were observed in tumor size. Significant differences $(P<0.01)$ were observed between the subtypes for the histological grade (Grade I compared to Grades II and III combined).

Higher histologic grade (Grade II/III) was strongly associated with HER2 type (odds ratio (OR) 3.84; 95\% CI $1.80,7.81$ ) and basal-like type (OR 7.43; 95\% CI 2.73, 25.45) compared to the reference ER/PR+ Her2- type (Figure 1). More specifically, the histological grade of ER/PR + HER2-, in contrast with HER2 type and basallike, was strongly associated with lower histologic grade (Grade I).

Protein expression and genetic mutation overall and by each intrinsic subtype are shown in Table 3. Overall, EGFR was expressed by $16.0 \%$ of patients, PTEN expression was reduced in $50.9 \%$ of patients and IGF-1R expression was $85.9 \%$. Bcl-2 expression (Figure 2a) was $65.0 \%$ and c-Kit expression (Figure $2 \mathrm{~b}$ ) was $7.1 \%$; however, there was no c-Kit expression observed in patients who were ER/PR + 
Table 2 Clinicopathological features for intrinsic subtypes

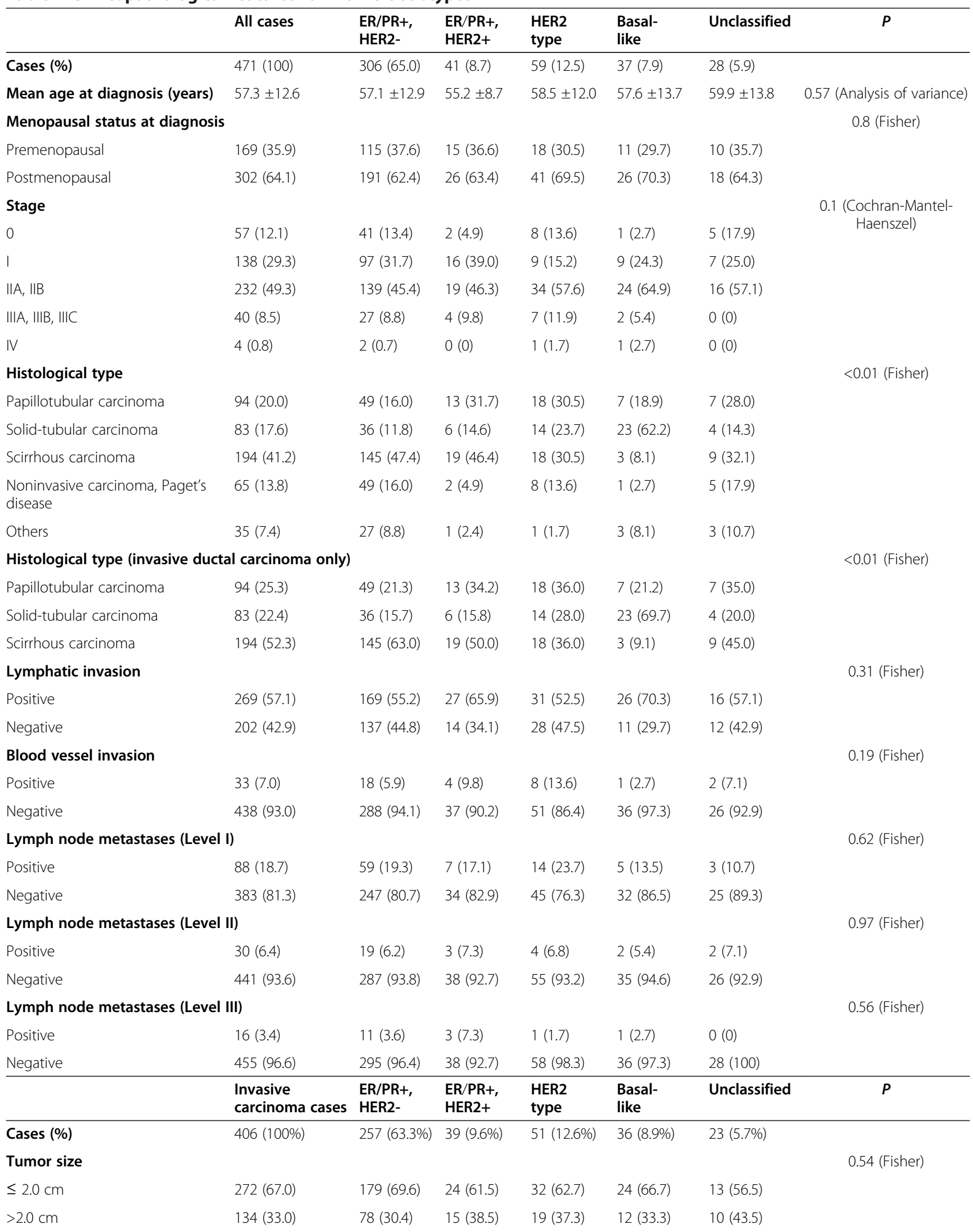


Table 2 Clinicopathological features for intrinsic subtypes (Continued)

\begin{tabular}{lllllll}
\hline Histological grade (total score) & & & & & $<0.01$ (Fisher) \\
Grade I & $200(49.3)$ & $148(57.6)$ & $21(53.8)$ & $14(27.4)$ & $5(13.9)$ & $12(52.2)$ \\
Grade II or III & $201(49.5)$ & $106(41.2)$ & $18(46.2)$ & $36(70.6)$ & $31(86.1)$ & $10(43.5)$ \\
Unknown & $5(1.2)$ & $3(1.2)$ & $0(0)$ & $1(2.0)$ & $0(0)$ & $1(4.3)$ \\
\hline
\end{tabular}

HER2+. Overall, c-Met expression was $72.6 \%$, and HIF- $1 \alpha$ expression was $34.1 \%$. The expression of PDGFRA was $86.9 \%$. The expression of survivin was $82.4 \%$, VEGFR2 was $68.1 \%$ and VEGF-A was $60.4 \%$. Significant differences were observed between each subtype for EGFR positivity, PTEN reduction, Bcl-2 positivity, c-Kit, c-Met and survivin. Exon 9 of PIK3CA was difficult to measure with paraffin blocks, so there were only 91 cases of successful measurements. Out of those, somatic mutation was observed in eight cases (8.8\%). In exon 20 of PIK3CA, somatic mutation was observed in 28 (7.8\%) out of 357 measurable cases.

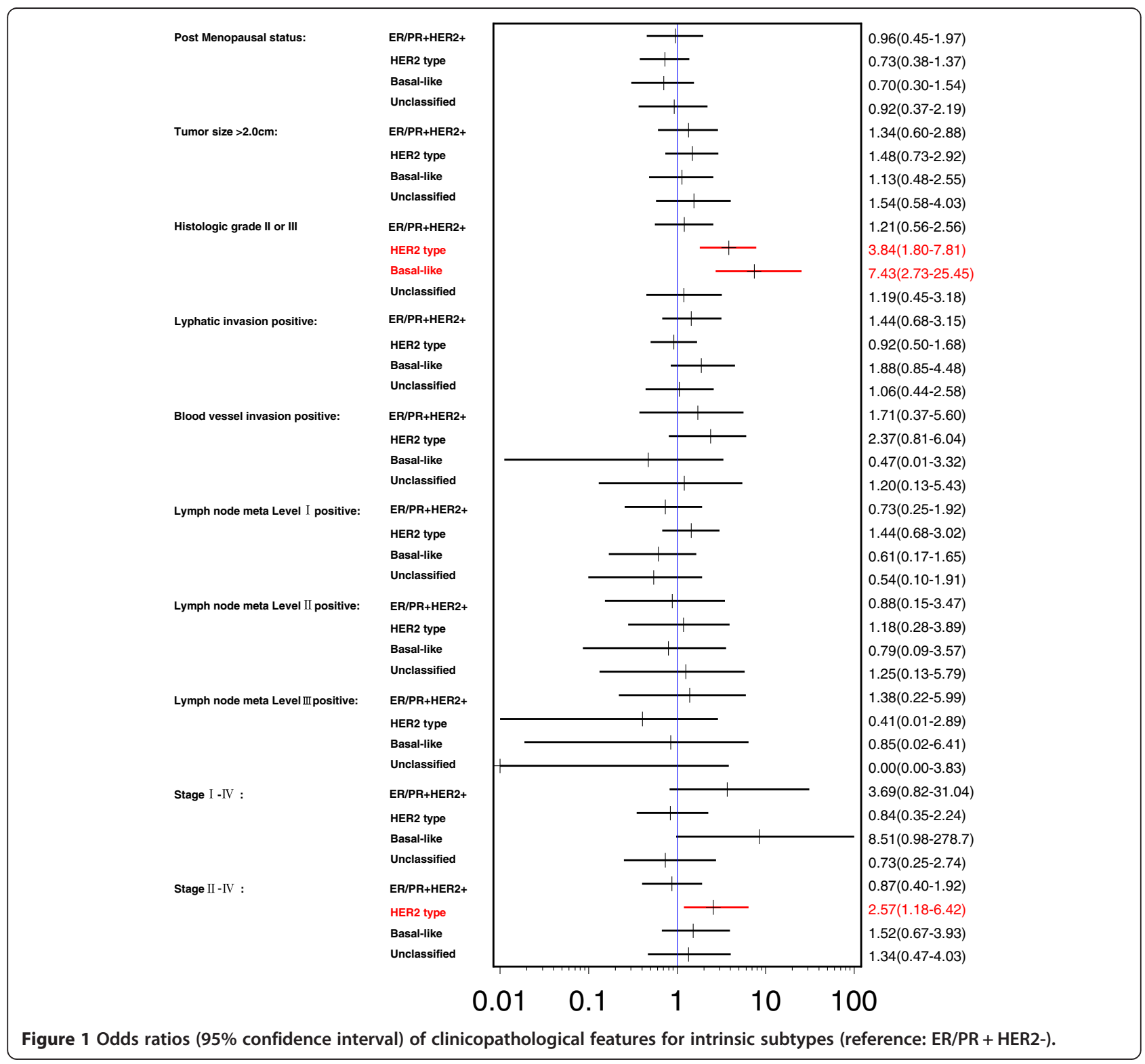


Table 3 Protein expression and genetic mutation by intrinsic subtypes

\begin{tabular}{|c|c|c|c|c|c|c|c|}
\hline & All cases & ER/PR + HER2- & ER/PR + HER2+ & HER2 type & Basal-like & Unclassified & $P$ \\
\hline Cases (\%) & $471(100)$ & $306(65.0)$ & $41(8.7)$ & $59(12.5)$ & $37(7.9)$ & $28(5.9)$ & \\
\hline EGFR & & & & & & & $<0.01$ \\
\hline Positive & $74(16.0)$ & $16(5.4)$ & $5(12.5)$ & 19 (32.8) & $34(91.9)$ & $0(0)$ & \\
\hline Negative & $388(84.0)$ & $283(94.6)$ & $35(87.5)$ & $39(67.2)$ & $3(8.1)$ & $28(100)$ & \\
\hline Missing & 9 & 7 & 1 & 1 & & & \\
\hline PTEN & & & & & & & $<0.01$ \\
\hline Reduced & $234(50.9)$ & $156(52.7)$ & $18(43.9)$ & $16(27.6)$ & $28(75.7)$ & $16(57.1)$ & \\
\hline Normal & $226(49.1)$ & $140(47.3)$ & $23(56.1)$ & $42(72.4)$ & $9(24.3)$ & $12(42.9)$ & \\
\hline Missing & 11 & 10 & & 1 & & & \\
\hline IGF-1R & & & & & & & 0.77 \\
\hline Positive & 397 (85.9) & 255 (85.6) & $36(87.8)$ & $50(86.2)$ & $30(81.1)$ & $26(92.9)$ & \\
\hline Negative & $65(14.1)$ & $43(14.4)$ & $5(12.2)$ & $8(13.8)$ & $7(18.9)$ & $2(7.1)$ & \\
\hline Missing & 9 & 8 & & 1 & & & \\
\hline $\mathrm{Bcl}-2$ & & & & & & & $<0.01$ \\
\hline Positive & $303(65.0)$ & $249(83.0)$ & $27(67.5)$ & $7(12.1)$ & $6(16.2)$ & $14(50.0)$ & \\
\hline Negative & $160(35.0)$ & $51(17.0)$ & $13(32.5)$ & $51(87.9)$ & $31(83.8)$ & $14(50.0)$ & \\
\hline Missing & 8 & 6 & 1 & 1 & & & \\
\hline c-Kit & & & & & & & $<0.01$ \\
\hline Positive & $33(7.1)$ & $15(5.0)$ & $0(0)$ & $7(12.1)$ & $10(27.0)$ & $1(3.6)$ & \\
\hline Negative & $433(92.9)$ & $287(95.0)$ & $41(100)$ & $51(87.9)$ & $27(73.0)$ & $27(96.4)$ & \\
\hline Missing & 5 & 4 & & 1 & & & \\
\hline c-Met & & & & & & & 0.03 \\
\hline Positive & $328(72.6)$ & $203(69.5)$ & $34(82.9)$ & $47(85.5)$ & $28(75.7)$ & $16(59.3)$ & \\
\hline Negative & $124(27.4)$ & $89(30.5)$ & $7(17.1)$ & $8(14.5)$ & $9(24.3)$ & $11(40.7)$ & \\
\hline Missing & 19 & 15 & & 4 & & 1 & \\
\hline HIF-1a & & & & & & & 0.76 \\
\hline Positive & $159(34.1)$ & $110(36.4)$ & $12(29.3)$ & $18(31.0)$ & 11 (29.7) & $8(28.6)$ & \\
\hline Negative & 307 (65.9) & $192(63.6)$ & $29(70.7)$ & $40(69.0)$ & $26(70.2)$ & $20(71.4)$ & \\
\hline Missing & 5 & 4 & & & & & \\
\hline PDGFRA & & & & & & & 0.49 \\
\hline Positive & $393(86.9)$ & 255 (87.6) & $34(85.0)$ & $52(91.2)$ & $30(81.1)$ & $22(81.5)$ & \\
\hline Negative & $59(13.1)$ & $36(12.4)$ & $6(15.0)$ & $5(8.8)$ & $7(18.9)$ & $5(18.5)$ & \\
\hline Missing & 19 & 15 & 1 & 2 & & 1 & \\
\hline Survivin & & & & & & & 0.02 \\
\hline Positive & $383(82.4)$ & $240(79.5)$ & $34(85.0)$ & $56(96.6)$ & $30(81.1)$ & $23(82.1)$ & \\
\hline Negative & $82(17.6)$ & $62(20.5)$ & $6(15.0)$ & $2(3.4)$ & $7(18.9)$ & $5(18.9)$ & \\
\hline Missing & 6 & 4 & 1 & 1 & & & \\
\hline VEGFR2 & & & & & & & 0.59 \\
\hline Positive & $318(68.1)$ & $206(68.0)$ & $25(61.0)$ & 44 (75.9) & $25(67.6)$ & 18 (64.3) & \\
\hline Negative & 149 (31.9) & $97(32.0)$ & $16(39.0)$ & $14(24.1)$ & $12(32.4)$ & $10(35.7)$ & \\
\hline Missing & 4 & 3 & & 1 & & & \\
\hline VEGF-A & & & & & & & 0.14 \\
\hline Positive & $279(60.4)$ & $180(60.0)$ & $25(61.0)$ & $42(72.4)$ & 18 (48.6) & $14(50.0)$ & \\
\hline Negative & 183 (39.6) & $118(40.0)$ & $16(39.0)$ & $16(27.6)$ & $19(51.4)$ & $14(50.0)$ & \\
\hline
\end{tabular}


Table 3 Protein expression and genetic mutation by intrinsic subtypes (Continued)

\begin{tabular}{|c|c|c|c|c|c|c|c|}
\hline Missing & 9 & 8 & & 1 & & & \\
\hline \multicolumn{7}{|c|}{ PIK3CA exon 9} & 0.94 \\
\hline Mutated & $8(8.8)$ & $6(9.7)$ & $0(0)$ & $1(10.0)$ & $0(0)$ & $1(14.3)$ & \\
\hline Wild type & $83(91.2)$ & $56(90.3)$ & $6(100)$ & $9(90.0)$ & $6(100)$ & $6(85.7)$ & \\
\hline Missing & 380 & 45 & 35 & 49 & 31 & 22 & \\
\hline \multicolumn{7}{|c|}{ PIK3CA exon 20} & 0.17 \\
\hline Mutated & $28(7.8)$ & $20(8.7)$ & $4(14.3)$ & $1(2.2)$ & $3(10.3)$ & $0(0)$ & \\
\hline Wild type & $329(92.2)$ & $211(91.3)$ & $24(85.7)$ & $44(97.8)$ & $26(89.7)$ & $24(100)$ & \\
\hline Missing & 114 & 75 & 13 & 14 & 8 & 4 & \\
\hline
\end{tabular}

EGFR: epidermal growth factor receptor, PTEN: phosphatase and tensin homolog deleted on chromosome 10, IGF-1R: insulin-like growth factor-1 receptor, Bcl-2: B-cell lymphoma 2, c-Met: hepatocyte growth factor receptor, HIF-1a: hypoxia-inducible factor 1-alpha, PDGFRA: alpha-type platelet-derived growth factor receptor, VEGFR2: vascular endothelial growth factor receptor 2, VEGF-A: vascular endothelial growth factor $A$.

Figure 3 shows associations between biomarker expressions and intrinsic subtypes with odds ratios when $\mathrm{ER} / \mathrm{PR}+\mathrm{HER} 2$ - is set as a reference group. EGFR expression was strongly associated with HER2 type (OR 9.64; 95\% CI 3.76, 20.53) and basal-like type (OR 104.55;

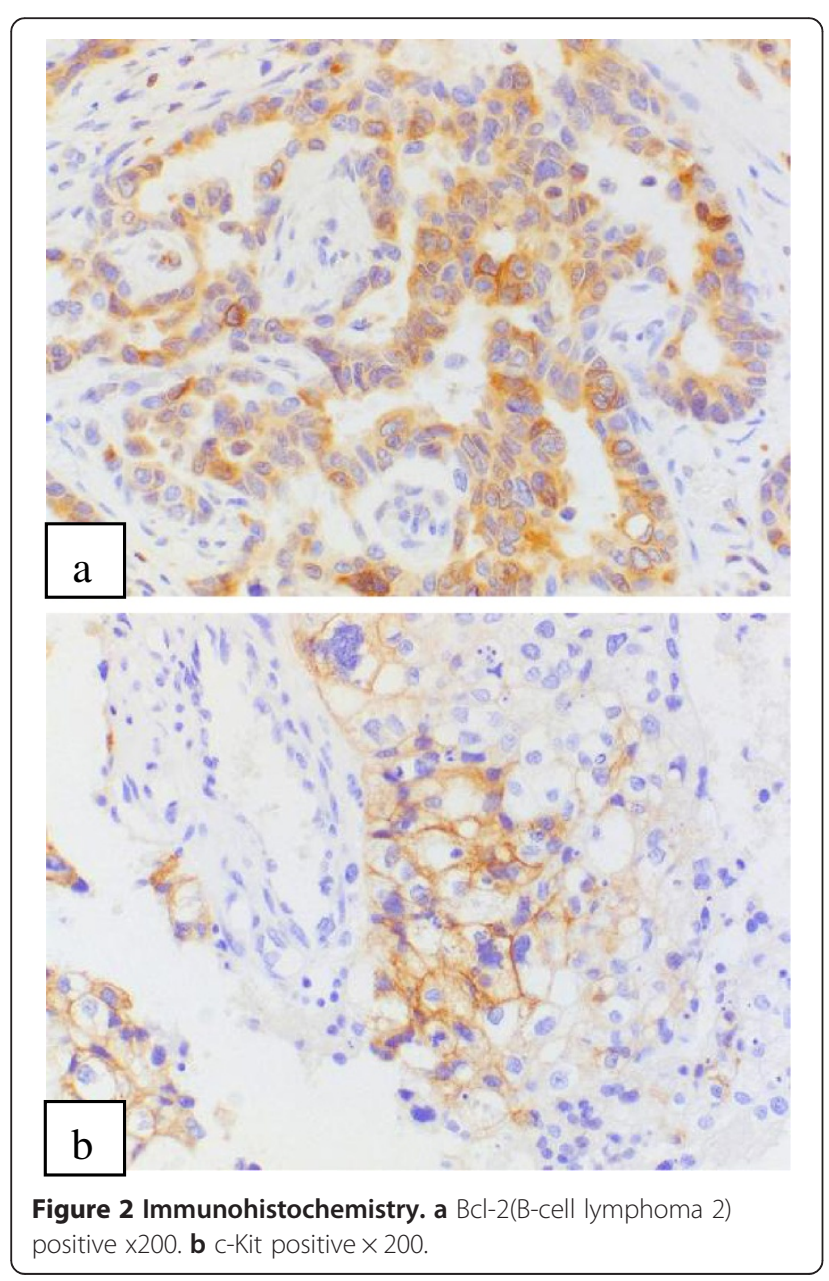

95\% CI 41.51, 856.77). PTEN reduction was associated with basal-like type (OR 2.57; 95\% CI 1.11, 6.37) and inversely associated with HER2 type (OR 0.31 ; 95\% CI $0.16,0.63)$. Bcl-2 expression was inversely associated with all the subtypes including ER/PR + HER2+, HER2 type, basal-like and unclassified types. c-Kit expression was associated with basal-like type, and c-Met and survivin expressions were associated with HER2 type.

When each biomarker expression was compared between each subtype, with ER/PR + HER2- as a reference (Table 4), the expression of Bcl-2 was lower in ER/PR + HER2+, and expression of c-Kit was not observed. The PTEN reduction and $\mathrm{Bcl}-2$ expression were lower in HER2 type, and the expression of EGFR, c-Met and survivin was significantly higher. The expression of EGFR and $\mathrm{c}$-Kit and the PTEN reduction were significantly higher in the basal-like type and expression of $\mathrm{Bcl}-2$ was significantly lower. The expression of Bcl-2 was significantly lower in the unclassified type.

The expression of biomarkers whose expression significantly differed between subtypes, was compared with that of ER, PR, HER2 and EGFR, on which subtyping was made (Table 5). PTEN reduction showed a significant difference between HER2 positive and negative groups, and was significantly higher in the reduced expression group $(P<0.01)$. Expression of Bcl-2 was significantly higher in ER positive group $(P<0.01)$, PR positive group $(P<0.01)$, HER2 negative group $(P<0.01)$, and EGFR negative group $(P<0.01)$, respectively, compared to the referent groups. c-kit expression was significantly lower in ER positive group $(P<0.01)$, PR positive group $(\mathrm{p}<0.01)$, and EGFR negative group $(P<0.01)$, respectively, compared to the referent groups. c-Met expression was positive rate significantly higher in HER2 positive group $(P<0.01)$ and EGFR positive group $(P=0.046)$. The survivin positive rate showed significant differences between ER positive and negative, and HER2 positive and negative groups, and was 


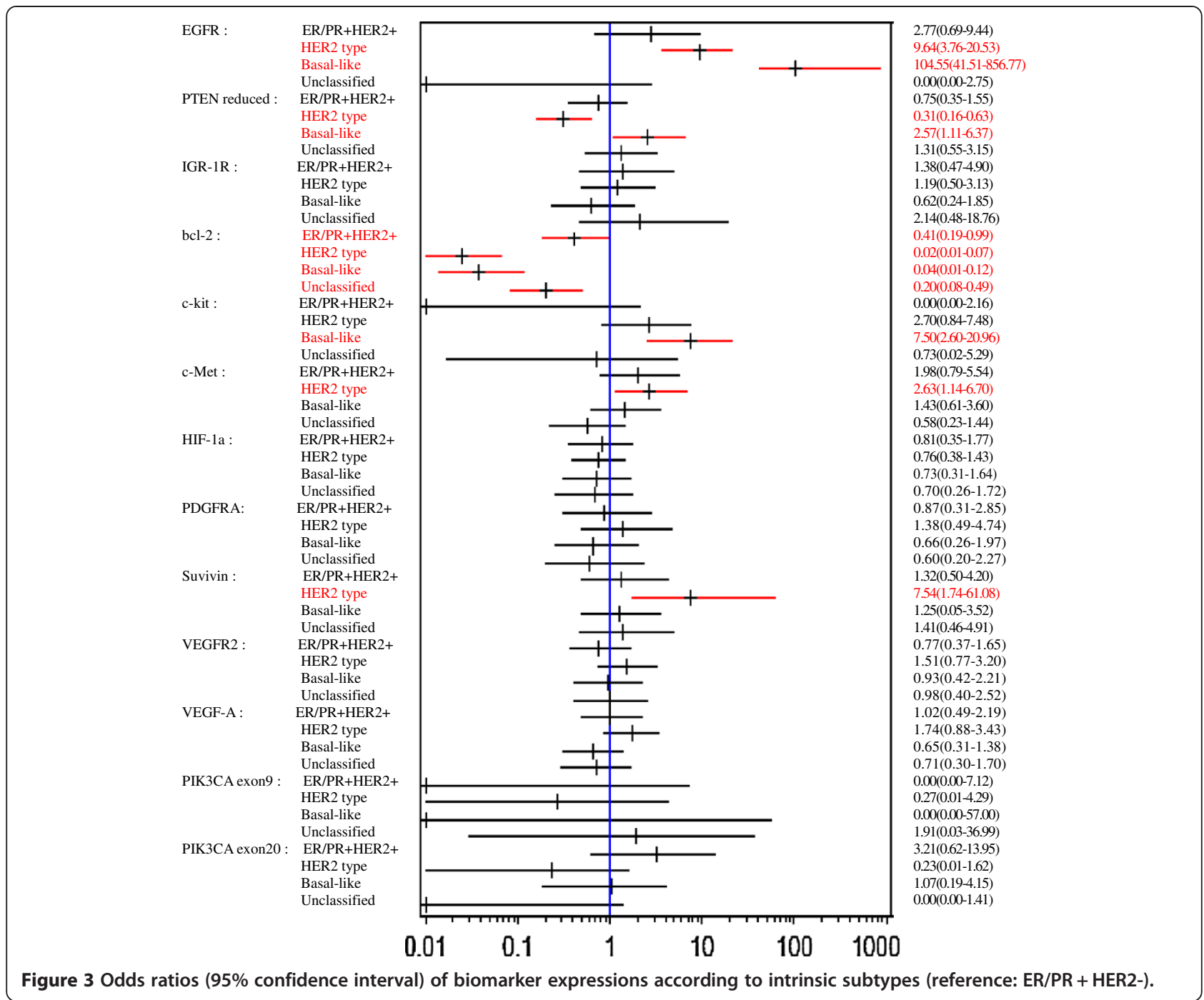

significantly higher in ER negative group $(P=0.03)$, and HER2 positive group $(P<0.01)$.

\section{Discussion}

This study describes the distribution of the IHC-intrinsic tumor subtypes, ER/PR + HER2-, ER/PR + HER2+, HER2 type, basal-like and unclassified, among Japanese patients with breast cancer. Clinicopathological characteristics of each intrinsic subtype are also presented. The present study further provides new evidence of the biomarker expression profile of each intrinsic subtype, which has scarcely been examined elsewhere.

\section{Distribution of intrinsic subtypes}

Distribution of intrinsic subtypes in this study with the proportion of ER/PR + HER2- (65.0\%), ER/PR + HER2+ (8.7\%), HER2 type (12.5\%), basal-like (7.9\%) and unclassified $(5.9 \%)$ was not essentially different from those reported elsewhere, as shown in Table 6 that shows subtype distributions in different populations $[2,3,6]$.

\section{ER/PR + HER2- subtype}

In our investigation, ER/PR + HER2- had a lower histological grade, higher Bcl-2 expression and lower EGFR expression compared to the other subtypes. This profile may play a role in the better prognosis reported for the ER/PR + HER2-.

The histological grade of ER/PR + HER2- was the lowest among the five subtypes, and it was significantly lower than for the HER2 and basal-like types. Among biomarkers measured, Bcl-2 expression was significantly higher in ER/PR + HER2- than the other subtypes, whereas EGFR expression was as low as 5.4\%, which was significantly lower than HER2 and basal-like types. EGFR expression was reported to be an independently worse prognostic factor for breast cancer [7], whereas 
Table 4 Comparison of molecular profile of each intrinsic subtype

\begin{tabular}{|c|c|c|c|c|c|c|c|c|c|c|}
\hline & \multicolumn{2}{|c|}{ ER/PR + HER2- } & \multicolumn{2}{|c|}{ ER/PR + HER2+ } & \multicolumn{2}{|c|}{ HER2 type } & \multicolumn{2}{|c|}{ Basal-like } & \multicolumn{2}{|c|}{ Unclassified } \\
\hline & $n$ & OR & $n$ & OR & $n$ & OR & $n$ & OR & $n$ & OR \\
\hline \multicolumn{11}{|l|}{ EGFR } \\
\hline Positive & 16 & 1.0 (Ref) & 5 & $2.77(0.69,9.44)$ & 19 & $9.64(3.76,20.53)$ & 34 & $104.55(41.51,856.77)$ & 0 & $0.00(0.00,2.75)$ \\
\hline Negative & 283 & & 35 & & 39 & & 3 & & 28 & \\
\hline \multicolumn{11}{|l|}{ PTEN } \\
\hline Reduced & 156 & 1.0 (Ref) & 18 & $0.75(0.35,1.55)$ & 16 & $0.31(0.16,0.63)$ & 28 & $2.57(1.11,6.37)$ & 16 & $1.31(0.55,3.15)$ \\
\hline Normal & 140 & & 23 & & 42 & & 9 & & 12 & \\
\hline \multicolumn{11}{|l|}{$\mathrm{Bcl}-2$} \\
\hline Positive & 249 & 1.0 (Ref) & 27 & $0.41(0.19,0.99)$ & 7 & $0.02(0.01,0.07)$ & 6 & $0.04(0.01,0.12)$ & 14 & $0.20(0.08,0.49)$ \\
\hline Negative & 51 & & 13 & & 51 & & 31 & & 14 & \\
\hline \multicolumn{11}{|l|}{ c-Kit } \\
\hline Positive & 15 & 1.0 (Ref) & 0 & $0.00(0.00,2.16)$ & 7 & $2.70(0.84,7.48)$ & 10 & $7.50(2.60,20.96)$ & 1 & $0.73(0.02,5.29)$ \\
\hline Negative & 287 & & 41 & & 51 & & 27 & & 27 & \\
\hline \multicolumn{11}{|l|}{ c-Met } \\
\hline Positive & 203 & 1.0 (Ref) & 34 & $1.98(0.79,5.54)$ & 47 & $2.63(1.14,6.70)$ & 28 & $1.43(0.61,3.60)$ & 16 & $0.58(0.23,1.44)$ \\
\hline Negative & 89 & & 7 & & 8 & & 9 & & 11 & \\
\hline \multicolumn{11}{|l|}{ Survivin } \\
\hline Positive & 240 & 1.0 (Ref) & 34 & $1.32(0.50,4.20)$ & 56 & $7.54(1.74,61.08)$ & 30 & $1.25(0.05,3.52)$ & 23 & $1.41(0.46,4.91)$ \\
\hline Negative & 62 & & 6 & & 2 & & 7 & & 5 & \\
\hline
\end{tabular}

Results are odds ratio (OR) adjusted by age and $95 \%$ confidence interval.

EGFR: epidermal growth factor receptor, PTEN: phosphatase and tensin homolog deleted on chromosome 10, Bcl-2: B-cell lymphoma 2, c-Met: hepatocyte growth factor receptor.

Table 5 Expression of ER, PR, HER 2 and EGFR by biomarkers whose expression significantly differed between subtypes

\begin{tabular}{|c|c|c|c|c|c|c|c|c|c|c|c|c|}
\hline \multirow[b]{2}{*}{ Biomarkers } & \multicolumn{2}{|l|}{ ER } & \multirow[t]{2}{*}{$P$} & \multicolumn{2}{|l|}{ PR } & \multirow[t]{2}{*}{$P$} & \multicolumn{2}{|l|}{ HER2 } & \multirow[t]{2}{*}{$P$} & \multicolumn{2}{|l|}{ EGFR } & \multirow[t]{2}{*}{$P$} \\
\hline & $\begin{array}{l}\text { Positive } \\
(\%)\end{array}$ & $\begin{array}{l}\text { Negative } \\
(\%)\end{array}$ & & $\begin{array}{l}\text { Positive } \\
(\%)\end{array}$ & $\begin{array}{l}\text { Negative } \\
(\%)\end{array}$ & & $\begin{array}{l}\text { Positive } \\
(\%)\end{array}$ & $\begin{array}{l}\text { Negative } \\
(\%)\end{array}$ & & $\begin{array}{l}\text { Positive } \\
(\%)\end{array}$ & $\begin{array}{l}\text { Negative } \\
\text { (\%) }\end{array}$ & \\
\hline PTEN & & & 0.76 & & & 0.10 & & & $<0.01$ & & & 0.80 \\
\hline Reduced & $163(50.3)$ & $71(52.2)$ & & $134(47.7)$ & $100(55.9)$ & & $34(34.3)$ & $200(55.4)$ & & $39(52.7)$ & $195(50.9)$ & \\
\hline Normal & $161(49.7)$ & $65(47.8)$ & & $147(52.3)$ & $79(44.1)$ & & $65(65.7)$ & $161(44.6)$ & & 35 (47.3) & $188(49.1)$ & \\
\hline $\mathrm{Bcl}-2$ & & & $<0.01$ & & & $<0.01$ & & & $<0.01$ & & & $<0.01$ \\
\hline Positive & $268(82.0)$ & $35(25.7)$ & & $238(83.2)$ & 65 (36.7) & & $34(34.7)$ & $269(73.7)$ & & $20(27.4)$ & $279(72.5)$ & \\
\hline Negative & $59(18.0)$ & $101(74.3)$ & & 48 (16.8) & $112(63.3)$ & & $64(65.3)$ & $96(26.3)$ & & $53(73.4)$ & $106(27.5)$ & \\
\hline c-Kit & & & $<0.01$ & & & $<0.01$ & & & 1.00 & & & $<0.01$ \\
\hline Positive & $15(4.5)$ & 18 (13.2) & & $11(3.8)$ & $22(12.3)$ & & $7(7.1)$ & $26(7.1)$ & & 16 (21.6) & $16(4.1)$ & \\
\hline Negative & 315 (95.5) & $118(86.8)$ & & $276(96.2)$ & $157(87.7)$ & & $92(92.9)$ & 341 (92.9) & & $58(78.4)$ & 371 (95.9) & \\
\hline c-Met & & & 0.42 & & & 0.16 & & & $<0.01$ & & & 0.046 \\
\hline Positive & $229(71.3)$ & 99 (75.6) & & $194(70.0)$ & 134 (76.6) & & $81(84.4)$ & 247 (69.4) & & $60(82.2)$ & 267 (70.8) & \\
\hline Negative & $92(28.7)$ & $32(24.4)$ & & $83(30.0)$ & $41(23.4)$ & & 15 (15.6) & 109 (30.6) & & $13(17.8)$ & $110(29.2)$ & \\
\hline Survivin & & & 0.03 & & & 0.06 & & & $<0.01$ & & & 0.24 \\
\hline Positive & $263(80.0)$ & $120(88.2)$ & & $228(79.7)$ & 155 (86.6) & & $90(91.8)$ & 293 (79.8) & & $64(87.7)$ & $314(81.1)$ & \\
\hline Negative & $66(20.0)$ & 16 (11.8) & & $58(20.3)$ & $24(13.4)$ & & $8(8.2)$ & $74(20.2)$ & & 9 (12.3) & 73 (18.9) & \\
\hline
\end{tabular}

Fisher's exact probability test was used for statistical analysis.

ER: estrogen receptor, PR: progesterone receptor, HER2: human epidermal growth factor receptor type 2, EGFR: epidermal growth factor receptor,

PTEN: phosphatase and tensin homolog deleted on chromosome 10, Bcl-2: B-cell lymphoma 2, c-Met: hepatocyte growth factor receptor. 
Bcl-2 expression is known to be a favorable prognostic factor for breast cancer.

Bcl-2 expression has been reported to correlate with ER expression [7], and to be inversely correlated with EGFR expression, HER2 expression and histological grade $[7,8]$. The better prognosis that is seen for Bcl-2positive breast cancer had thus been attributed to its higher prevalence of ER expression; however, Dawson et al. [9] demonstrated Bcl-2 expression to be associated with a good prognosis independent of ER expression, by comparing the associations between Bcl-2 expression and the prognosis of an ER positive group with that of an ER negative group separately.

\section{ER/PR + HER2 + subtype}

There was no significant difference in the clinicopathological features between ER/PR + HER2- and ER/PR + HER2+ in this investigation. The prevalence of $\mathrm{Bcl}-2$ expression in ER/PR + HER2 + was lower than that in ER/PR + HER2-. Dawson et al. [9] demonstrated both Bcl-2 negativity and HER2 positivity to be associated with a worse prognosis, and the group with the profile of Bcl-2 negative combined with HER2 positive showed the shortest survival. Taken together, the prognosis of ER/PR + HER2+ is thus expected to be worse than that of ER/PR + HER2-, and this has, in fact, been reported $[5,6]$.

\section{HER2 type}

When the clinicopathological characteristics of HER2 type were examined, higher histological grade (Grade II/ III compared to Grade I) was found to be significantly associated with HER2 type compared to ER/PR + HER2. Kurebayashi et al. [5] and Shibuta et al. [6] also reported a significant difference between the subtypes of histological grades and the nuclear grades.

In the current study, HER2-overexpressing tumors had a higher histologic grade, a higher positive rate of c-Met, survivin and EGFR, and a lower prevalence of PTEN reduction and Bcl-2 than ER/PR + HER2-. These differences in the molecular characteristics between ER/PR + HER2- and HER2 type may contribute to the reported worse prognosis of HER2 type in comparison to ER/PR + HER2- [2,4-6].
The HER2 signaling pathway is related to EGFR, PTEN, IGF-1R, c-Met and PIK3CA. Among these biomarkers, our data demonstrated the proportion of PTEN reduction to be significantly lower whereas the expression of EGFR and c-Met was significantly higher in HER2 type than in ER/PR + HER2-. However, no significant differences between subtypes were observed in expression of IGF-1R or PIK3CA mutation frequency. Moreover, in this investigation, Bcl-2 expression was significantly lower and the survivin expression was significantly higher in HER2 type.

The Phosphoinositide 3-kinase-Akt also known as protein kinase $B$ or PKB pathway is downstream of HER2 and is activated by PIK3CA mutation and PTEN loss $[10,11]$. PIK3CA mutation is reported to be observed in $25 \%$ to $40 \%$ of all breast cancers. In this investigation, PIK3CA mutation in exon 20 in the HER2 type was found in only one out of the 45 measurable cases (2.2\%). PTEN reduction was observed in $27.6 \%$ of the HER2 type cases, and the proportion was smaller than that for ER/PR + HER2-. Capodanno et al. [10] and PerezTenorio et al. [12] also reported the proportion of PTEN reduction to be smaller in the group with HER2 overexpression compared to luminal types.

c-Met is known to be involved in several biological functions, including cell proliferation, cell survival, angiogenesis, cancer cell invasion and metastasis. c-Met has been reported to be frequently expressed in HER2 positive breast cancers, and in this investigation also, c-Met positivity was high in HER2 type (85.5\%) and ER/PR + HER2+ type (82.9\%). Regarding sensitivity to treatment, there have been reports suggesting that c-Met expression may be involved in resistance to trastuzumab [13], and thus the c-Met expression status should be considered when selecting the optimal treatment for HER2 type cases.

The EGFR positive rate of HER2 type was the second highest after basal-like type among the subtypes. EGFR positivity is reported to be a worse prognostic factor, and is also reported to be high in HER2 positive breast cancer [14-21].

The prevalence of Bcl-2 expression in HER2 type was significantly lower than that in ER/PR + HER2-. Dawson et al. [9] demonstrated $\mathrm{Bcl}-2$ positivity to be a favorable prognostic factor independent of HER2 positivity.

Table 6 Comparison of intrinsic subtypes distribution in different populations

\begin{tabular}{|c|c|c|c|c|c|c|c|}
\hline Reference & Country & All patients (\%) & ER/PR + HER2- & ER/PR + HER2+ & HER2 type & Basel-like & Unclassified \\
\hline Our research & Japan & $471(100)$ & $306(65.0)$ & $41(8.7)$ & $59(12.5)$ & $37(7.9)$ & $28(5.9)$ \\
\hline Shibuta et al. [6] & Japan & $4,266(100)$ & $3,046(71)$ & $321(8)$ & $398(9)$ & \multicolumn{2}{|c|}{$501(12)$} \\
\hline \multirow[t]{3}{*}{ Carey et al. [2] } & US & $496(100)$ & $255(51.4)$ & $77(15.5)$ & $33(6.7)$ & $100(20.1)$ & $31(6.3)$ \\
\hline & African American & $196(100)$ & $93(47.4)$ & $25(12.8)$ & $16(8.2)$ & $52(26.5)$ & $10(5.1)$ \\
\hline & Non-African American & $300(100)$ & $162(54)$ & $52(17.3)$ & $17(5.7)$ & $48(16)$ & $21(7)$ \\
\hline Tamimi et al. [3] & US & $2,249(100)$ & $1,650(73)$ & $116(5)$ & $128(6)$ & $245(11)$ & $110(5)$ \\
\hline
\end{tabular}


The positive rate of survivin was $96.6 \%$. There are many reports describing frequent expression of survivin in cancer cells, with a prevalence ranging from $60 \%$ to $80 \%$ in breast cancers [13,22]. Survivin is an apoptosissuppressing factor, and is reported to be an independent factor for a poor prognosis [22]. In our study, survivin positive rate was relatively high in the HER2 positive group, ER negative group and PR negative group (Table 5). Ryan et al. also reported the survivin positive rate to be as high as $90 \%$ and its expression level was higher in ER negative, PR negative and HER2 positive breast cancers [23]. Asanuma et al. [16] also found the survivin positive rate to be higher in HER2 positive cancer and furthermore showed survivin expression to be more frequent in EGFR positive cancer.

In summary, compared to ER/PR + HER2-, HER2 type showed a higher histologic grade, higher positive rates of c-Met, survivin and EGFR, and a lower prevalence of PTEN reduction and $\mathrm{Bcl}-2$. These differences in the molecular characteristics between ER/PR + HER2- and HER2 type may explain the reported worse prognosis of HER2 type in comparison to ER/PR + HER2- [2,4-6].

\section{Basal-like type}

In our investigation, histological grade of basal-like type was significantly higher than for ER/PR + HER2-, which was concordant with past reports [2-6]. The distribution of each histologic type among basal-like type breast tumors showed the frequency of solid-tubular carcinoma to be the highest at $62.2 \%$, whereas scirrhous carcinoma was most prevalent among ER/PR + HER2- and ER/PR+ HER2+. Nakajima et al. [24] also reported the most prevalent histologic type in ER/PR + HER2- and ER/PR + HER2+ to be scirrhous carcinoma, while the frequency of solidtubular carcinoma was as high as that of scirrhous carcinoma at $34 \%$ in basal-like type [24]. A higher proportion of solid-tubular carcinoma in tumors of a basal-like subtype is also consistent with results by Tsuda et al., who found EGFR positivity in solidtubular carcinoma to be $17 \%$ - much higher than that in scirrhous carcinoma (6\%) and papilla-tubular carcinoma (3\%) [14]. It must be noted that EGFR expression was one of the criteria for the basal-like subtype classification in this study, and $91.9 \%$ of basal-like cases were positive for EGFR.

The prevalence of PTEN reduction in basal-like type tumors was significantly higher than that for ER/PR + HER2- in this study. López-Knowles et al. [25] also observed the rate of PTEN reduction to be higher than for the other subtypes, and Marty et al. [26] reported that PTEN reduction was more prevalent in basal-like type compared to HER2 type.

Regarding Bcl-2 expression in basal-like type tumors, the positive rate was significantly lower than that for
ER/PR + HER2- in this study. c-Kit expression has been reported to be observed in almost all normal breast tissues, while it is frequently diminished or lost in breast tumor tissues [27]. The c-Kit positive rate in breast cancer was reported as $14 \%$ by Nielson et al. [28] and $14.7 \%$ by Charpin et al. [24]. In our study, c-Kit expression was observed in $7.1 \%$ of patients overall. Its positive rate in basal-like type tumors was $27.0 \%$, which was significantly higher than that in ER/PR + HER2-. Our results showing the c-Kit positive rate to be higher in ER negative, PR negative and EGFR positive groups (Table 5) are consistent with the difference in the c-Kit positive rate between basal-like and ER/PR + HER2-. Tsuda et al. [14] reported a similar relationship of c-Kit expression with ER, PR and EGFR expressions. c-Kit expression is also known to be a worse prognostic factor for breast cancer [29].

From the above, there is a possibility that the characteristics of basal-like type, specifically its higher histological grades, higher rate of PTEN reduction, lower rate of $\mathrm{Bcl}-2$ positivity and higher rate of c-Kit positivity compared to ER/PR + HER2- type, may together help to explain why the prognosis of basal-like type is poorer than that for ER/PR + HER2- [2,4-6]. Moreover, since PTEN reduction is reported to correlate with Akt activity [26], the inhibition of Akt activation or suppression of c-Kit signals could thus become a target for treatment for basal-like type breast cancer.

\section{Unclassified type}

In this study, out of the triple negative (ER-, PR- and HER2-) cases, EGFR- and CK5/6- cases were considered to have an unclassified subtype. As reported above, the histological grade of basal-like tumors was significantly higher than those of ER/PR + HER2-, however there was no difference between unclassified and ER/PR + HER2-. A higher nuclear grade of basal-like triple-negative tumors compared with non-basal-like triple negative (the unclassified type in our study) was observed by Yamamoto et al. [30] as well.

The expression of Bcl-2 in the unclassified subtype was significantly lower compared to ER/PR + HER2-; however, it was higher than that of basal-like type.

Positive IGF-1R expression was higher in the unclassified group than in ER/PR + HER2- (OR 2.14; 95\% CI $0.48,18.76)$ though it was not significant, whereas that of basal-like type was lower than that for ER/PR + HER2-. Hartog et al. reported the expression of IGF-1R to be a worse prognostic factor in triple-negative breast tumors [31].

A lower expression of Bcl-2 and a higher expression of IGF-1R in unclassified tumors compared to ER/PR + HER2- were thus suggested to be partly involved in the 
reported worse prognosis of unclassified type cancer than ER/PR + HER2- $[2,4,5]$.

Although IGF-1R expression was a worse prognostic factor in triple-negative breast tumors, it was a favorable prognostic factor in ER positive breast tumors [31]. IGF$1 \mathrm{R}$ expression thus could be used for accurately selecting patients who are best indicated to undergo IGF-1Rtargeted therapy.

\section{Conclusion}

In this study, we clarified not only that the clinicopathological profiles, such as histological types and histological grades, vary between the breast cancer subtypes, but also that there are differences in the molecular expression profiles between subtypes. The reported differences in the prognosis between intrinsic subtypes may therefore be partly attributable to the differences in their molecular characteristics. Furthermore, the molecular characteristics of each subtype can be used as reference data when developing new treatments for breast cancer and for selecting patients who are sensitive or resistant to each therapy.

\section{Abbreviations}

bp: Base pair; BCl-2: B-cell lymphoma 2; CK5/6: Cytokeratin5/6; c-MET: Hepatocyte growth factor receptor; EGFR: Eepidermal growth factor receptor; ER: Estrogen receptor; HER 2: Human epidermal growth factor receptor type 2; HIF-1a: Hypoxia-inducible factor 1-alpha; IGF-1R: Insulin-like growth factor-1 receptor; IHC: Immunohistochemistry; OR: Odds ratio; PCR: Polymerase chain reaction; PDGFRA: Alpha-type platelet-derived growth factor receptor; PR: Progesterone receptor; PTEN: Phosphatase and tensin homolog deleted on chromosome 10; VEGFR2: Vascular endothelial growth factor receptor 2; VEGR-A: Vascular endothelial growth factor A: PIK3CA: Phosphatidylinositol-3-kinase, catalytic, alpha.

\section{Competing interests}

This study was conducted as a sponsored study of GlaxoSmithKline K.K. with its full financial support.

\section{Authors' contributions}

MT,TK,SK were involved in the review of literature, acquisition of data and drafting and completing the manuscript. NK participated in the design of the study and statistical analysis. TN carried out histopathological analysis. All authors read and approved the final manuscript.

\section{Acknowledgement}

We thank Dr Naohito Yamaguchi in Tokyo Women's Medical University for management for this research, and Akihiro Kobayashi who is an employee of GlaxoSmithKline, K.K. for assistance in data management and statistical analysis, and Dr Toshihiko Kaise who is an employee of GlaxoSmithKline, K.K. for getting mutation analysis results and critical review of the manuscript.

\footnotetext{
Author details

'Department of Surgery II, Tokyo Women's Medical University, 8-1 Kawada-cho, Shinjuku-ku, Tokyo 162-8666, Japan. ${ }^{2}$ Department of Hygiene and Public Health II, Tokyo Women's Medical University, 8-1 Kawada-cho, Shinjuku-ku, Tokyo 162-8666, Japan. ${ }^{3}$ Department of Pathology, Tokyo Women's Medical University, 8-1 Kawada-cho, Shinjuku-ku, Tokyo 162-8666, Japan.
}

Received: 28 March 2013 Accepted: 18 October 2013

Published: 18 November 2013

\section{References}

1. Sorlie T, Tibshirani R, Parker J, Hastie T, Marron JS, Nobel A, Deng S, Johnsen H, Pesich R, Geisler S, Demeter J, Perou CM, Lønning PE, Brown PO, Børresen-Dale AL, Botstein D: Repeated observation of breast tumor subtypes in independent gene expression data sets. Proc Natl Acad Sci U S A 2003, 100:8418-8423.

2. Carey LA, Perou CM, Livasy CA, Dressler LG, Cowan D, Conway K, Karaca G, Troester MA, Tse CK, Edmiston S, Deming SL, Geradts J, Cheang MC, Nielsen TO, Moorman PG, Earp HS, Millikan RC: Race, breast cancer subtypes, and survival in the Carolina Breast Cancer Study. JAMA 2006, 295:2492-2502.

3. Tamimi RM, Baer HJ, Marotti J, Galan M, Galaburda L, Fu Y, Deitz AC, Connolly JL, Schnitt SJ, Colditz GA, Collins LC: Comparison of molecular phenotypes of ductal carcinoma in situ and invasive breast cancer. Breast Cancer Res 2008, 10:1-9.

4. Millar EK, Graham PH, O'Toole SA, McNeil CM, Browne L, Morey AL, Eggleton S, Beretov J, Theocharous C, Capp A, Nasser E, Kearsley JH, Delaney G, Papadatos G, Fox C, Sutherland RL: Prediction of local recurrence, distant metastases, and death after breast-conserving therapy in early-stage invasive breast cancer using a five-biomarker panel. J Clin Oncol 2009, 27:4701-4708.

5. Kurebayashi J, Moriya T, Ishida T, Hirakawa H, Kurosumi M, Akiyama F. Kinoshita T, Takei H, Takahashi K, Ikeda M, Nakashima K: The prevalence of intrinsic subtypes and prognosis in breast cancer patients of different races. Breast 2007, 16:S72-S77.

6. Shibuta K, Ueo H, Furusawa H, Komaki K, Rai Y, Sagara Y, Kamada Y, Tamaki $\mathrm{N}$ : The relevance of intrinsic subtype to clinicopathological features and prognosis in 4,266 Japanese women with breast cancer. Breast Cancer 2011, 18:292-298.

7. Rolland P, Spendlove I, Madjd Z, Rakha EA, Patel P, Ellis IO, Durrant L: The p53 positive $\mathrm{Bcl}-2$ negative phenotype is an independent marker of prognosis in breast cancer. Int J Cancer 2007, 120:1311-1317.

8. Zhang GJ, Tsuda H, Adachi I, Fukutomi T, Yamamoto H, Hirohashi S: Prognostic indicators for breast cancer patients with one to three regional lymph node metastases, with special reference to alterations in expression levels of bcl-2, p53 and c-erbB-2 proteins. Jpn J Clin Oncol 1997, 27(6):371-377.

9. Dawson SJ, Makretsov N, Blows FM, Driver KE, Provenzano E, Le Quesne J, Baglietto L, Severi G, Giles GG, McLean CA, Callagy G, Green AR, Ellis I, Gelmon K, Turashvili G, Leung S, Aparicio S, Huntsman D, Caldas C, Pharoah $\mathrm{P}$ : BCL2 in breast cancer: a favourable prognostic marker across molecular subtypes and independent of adjuvant therapy received. $\mathrm{Br} J$ Cancer 2010, 103:668-675.

10. Capodanno A, Camerini A, Orlandini C, Baldini E, Resta ML, Bevilacqua G, Collecchi P: Dysregulated PI3K/Akt/PTEN pathway is a marker of a short disease-free survival in node-negative breast carcinoma. Hum Patho 2009, 40:1408-1417.

11. Pohlmann PR, Mayer IA, Mernaugh R: Resistance to trastuzumab in breast cancer. Clin Cancer Res 2009, 15(24):7479-7491.

12. Pérez-Tenorio G, Alkhori $L$, Olsson B, Waltersson MA, Nordenskjöld B, Rutqvist LE, Skoog L, Stål O: PIK3CA mutations and PTEN loss correlate with similar prognostic factors and are not mutually exclusive in breast cancer. Clin Cancer Res 2007, 13:3577-3584.

13. Shattuck DL, Miller JK, Carraway KL 3rd, Sweeney C: Met receptor contributes to trastuzumab resistance of Her2-overexpressing breast cancer cells. Cancer Res 2008, 68(5):1471-1477.

14. Tsuda H, Morita D, Kimura M, Shinto E, Ohtsuka Y, Matsubara O, Inazawa J, Tamaki K, Mochizuki H, Tamai S, Hiraide H: Correlation of KIT and EGFR overexpression with invasive ductal breast carcinoma of the solidtubular subtype, nuclear grade3, and mesenchymal or myoepithelial differentiation. Cancer Sci 2005, 96:48-53.

15. Nalwoga $H$, Arnes JB, Wabinga $H$, Akslen LA: Expreesions of EGFR and c-kit is associated with the basal-like phenotype in breast carcinomas of African women. J compilation APMIS 2008, 116:515-525.

16. Asanuma H, Torigoe T, Kamiguchi K, Hirohashi Y, Ohmura T, Hirata K, Sato $M$, Sato N: Survivin expression is regulated by coexpression of human epidermal growth factor receptor 2 and epidermal growth factor receptor via phosphatidylinositol 3-kinase/AKT signaling pathway in breast cancer cells. Cancer Res 2005, 65(23):11018-11025.

17. Tsuda H, Tani Y, Weisenberger J, Kitada S, Hasegawa T, Murata T, Tama S, Hirohashi S, Matsubara O, Natori T: Frequent KIT and epidermal growth factor receptor overexpressions in undifferentiated-type 
breast carcinomas with 'stem-cell-like' features. Cancer Sci 2005, 96:333-339.

18. Toyama T, Yamashita H, Kondo N, Okuda K, Takahashi S, Sasaki H, Sugiura H, Iwase H, Fujii Y: Frequently increased epidermal growth factor receptor (EGFR) copy numbers and decreased BRCA1 mRNA expression in Japanese triple-negative breast cancers. BMC Cancer 2008, 8:309.

19. Rimawi MF, Shetty PB, Weiss HL, Schiff R, Osborne CK, Chamness GC, Elledge RM: Epidermal growth factor receptor expression in breast cancer association with biologic phenotype and clinical outcomes. Cancer 2010, 116:1234-1242

20. Tsutsui S, Ohno S, Murakami S, Hachitanda Y, Oda S: Prognostic value of epidermal growth factor receptor (EGFR) and its relationship to the estrogen receptor status in 1029 patients with breast cancer. Breast Cancer Res Treat 2002, 24(71):67-75.

21. Lengyel E, Prechtel D, Resau JH, Gauger K, Welk A, Lindemann K, Salanti G, Richter T, Knudsen B, Vande Woude GF, Harbeck N: c-Met overexpression in node-positive breast cancer identifies patients with poor clinical outcome independent of Her2/neu. Int J Cancer 2005, 113:678-682.

22. Minakshi G, Altieri DC: Survivin as a global target of intrinsic tumor suppression networks. Cell Cycle 2009, 8(17):2708-2713.

23. Ryan BM, Konecny GE, Kahlert S, Wang HJ, Untch M, Meng G, Pegram MD, Podratz KC, Crown J, Slamon DJ, Duffy MJ: Survivin expression in breast cancer predicts clinical outcome and is associated with HER2, VEGF, urokinase plasminogen activator and PAI-1. Ann Oncol 2006, 17:597-604.

24. Nakajima H, Fujiwara I, Mizuta N, Sakaguchi K, Hachimine T, Tyumu K, Ichita $\mathrm{M}$, Konishi $\mathrm{H}$, Yanagisawa A: Estrogen receptor by immunohistochemical staining and an investigation on the prognosis of breast cancer from observing the expression of HER2. J Jpn Surg Assoc 2007, 68(9):2171-2177.

25. López-Knowles E, O'Toole SA, McNeil CM, Millar EK, Qiu MR, Crea P, Daly RJ, Musgrove EA, Sutherland RL: PI3K pathway activation in breast cancer is associated with the basel-like phenotype and cancer-specific mortality. Int J Cancer 2010, 126:1121-1131.

26. Marty B, Maire V, Gravier E, Rigaill G, Vincent-Salomon A, Kappler M, Lebigot I, Djelti F, Tourdès A, Gestraud P, Hupé P, Barillot E, Cruzalegui F, Tucker GC, Stern MH, Thiery JP, Hickman JA, Dubois T: Frequent PTEN genomic alteration and activated phosphatidylinositol 3-kinase pathway in basel-like breast cancer cells. Breast Cancer Res 2008, 10:R101.

27. Ko CD, Kim JS, Ko BG, Son BH, Kang HJ, Yoon HS, Cho EY, Gong G, Ahn SH: The meaning of the c-kit proto-oncogene product in malignant transformation in human mammary epithelium. Clin Exp Metastasis 2003, 20:593-597.

28. Nielsen TO, Hsu FD, Jensen K, Cheang M, Karaca G, Hu Z, HernandezBoussard T, Livasy C, Cowan D, Dressler L, Akslen LA, Ragaz J, Gown AM, Gilks CB, van de Rijn M, Perou CM: Immunohistochemical and clinical characterization of the basel-like subtype of invasive breast carcinoma. Clin Cancer Res 2004, 10:5367-5374.

29. Charpin C, Giusiano S, Charfi S, Secq V, Carpentier S, Andrac L, Lavaut MN, Allasia C, Bonnier P, Garcia S: Quantitative immunohistochemical expression of $\mathrm{c}$ Kit in breast carcinoma is predictive of patients outcome. Br J Cancer 2009, 101:48-54.

30. Yamamoto Y, Ibusuki M, Nakano M, Kawasoe T, Hiki R, Iwase H: Clinical significance of basel-like subtype in triple-negative breast cancer. Breast Cancer 2009, 16:260-267.

31. Hartog H, Horlings HM, van der Vegt B, Kreike B, Ajouaou A, van de Vijver MJ, Marike Boezen H, de Bock GH, van der Graaf WT, Wesseling J: Divergent effects of insulin-like growth factor-1 receptor expression on prognosis of estrogen receptor positive versus triple negative invasive ductal breast carcinoma. Breast Cancer Res Treat 2010, 129:725-736.

doi:10.1186/1477-7819-11-293

Cite this article as: Tamaki et al:: The relevance of the intrinsic subtype to the clinicopathological features and biomarkers in Japanese breast cancer patients. World Journal of Surgical Oncology 2013 11:293.

\section{Submit your next manuscript to BioMed Central and take full advantage of:}

- Convenient online submission

- Thorough peer review

- No space constraints or color figure charges

- Immediate publication on acceptance

- Inclusion in PubMed, CAS, Scopus and Google Scholar

- Research which is freely available for redistribution 